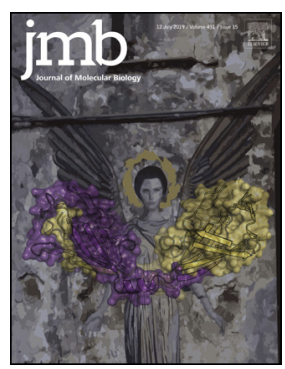

\title{
A Type III CRISPR Ancillary Ribonuclease Degrades Its Cyclic Oligoadenylate Activator
}

\author{
Januka S. Athukoralage, Shirley Graham, Sabine Grüschow, \\ Christophe Rouillon ${ }^{1}$ and Malcolm F. White
}

Biomedical Sciences Research Complex, School of Biology, University of St Andrews, North Haugh, St Andrews, Fife KY16 9ST, UK

Correspondence to Malcolm F. White: mfw2@st-andrews.ac.uk

https://doi.org/10.1016/j.jmb.2019.04.041

Edited by Konstantin Severinov

\begin{abstract}
Cyclic oligoadenylate ( $\mathrm{COA}$ ) secondary messengers are generated by type III CRISPR systems in response to viral infection. cOA allosterically activates the CRISPR ancillary ribonucleases Csx1/Csm6, which degrade RNA non-specifically using a HEPN (Higher Eukaryotes and Prokaryotes, Nucleotide binding) active site. This provides effective immunity but can also lead to growth arrest in infected cells, necessitating a means to deactivate the ribonuclease once viral infection has been cleared. In the crenarchaea, dedicated ring nucleases degrade $\mathrm{CA}_{4}$ (cOA consisting of 4 AMP units), but the equivalent enzyme has not been identified in bacteria. We

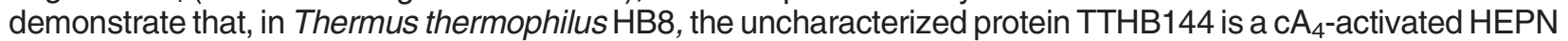
ribonuclease that also degrades its activator. TTHB144 binds and degrades $\mathrm{CA}_{4}$ at an N-terminal CARF (CRISPR-associated Rossman fold) domain. The two activities can be separated by site-directed mutagenesis. TTHB144 is thus the first example of a self-limiting CRISPR ribonuclease.

(C) 2019 The Author(s). Published by Elsevier Ltd. This is an open access article under the CC BY license (http:// creativecommons.org/licenses/by/4.0/).
\end{abstract}

\section{Introduction}

The CRISPR system provides prokaryotes with adaptive immunity against mobile genetic elements (reviewed in Refs. [1-3]). Type III (Csm/Cmr) CRISPR effector complexes harbor two nuclease activities for defense against mobile genetic elements: cleavage of foreign "target" RNA by the Cas7 subunit and degradation of single-stranded DNA by the HD nuclease domain (reviewed in Refs. [4,5]). In addition, effector complexes produce cyclic oligoadenylate (cOA) anti-viral signaling molecules that activate CRISPR ancillary proteins to potentiate the immune response [6,7]. On target RNA binding, the cyclase domain of the Cas 10 subunit polymerises ATP into COA, which consist of 3-6, $5^{\prime}$ to $3^{\prime}$-linked AMP subunits [6-9]. cOA acts as an "alarm signal" within cells and strongly stimulates the activity of the CRISPR ancillary ribonucleases Csx1 and Csm6 [6-8]. Csx1/Csm6 family proteins consist of a CARF (CRISPR-associated Rossman fold) domain that binds COA and a HEPN (Higher Eukaryotes and Prokaryotes Nucleotide binding) domain that pos- sesses weak ribonuclease activity in the absence of cOA $[10,11]$. Once stimulated by $\mathrm{cOA}$, the nonspecific RNA degradation activity of the Csm6 ribonuclease impacts both viral and cell growth [12]. Therefore, to recover from viral infection, cells require a mechanism for the removal of cOA. Sulfolobus solfataricus (Sso) encodes dedicated ring nucleases, which degrade the cyclic tetraadenylate $\left(\mathrm{cA}_{4}\right)$ activator and deactivate Csx1 [13]. Thus far, ring nucleases have only been identified in the crenarchaea, and, as highlighted by Mo and Marraffini [14], the enzyme(s) responsible for cOA degradation in bacteria remains unknown. The type III CRISPR system of the bacterium Thermus thermophilus HB8 (TTHB) has been investigated $[15,16]$, and its CRISPR ancillary ribonuclease TTHB152 was among the first shown to be activated by $\mathrm{CA}_{4}$ [6]. The type III CRISPR locus of $T$. thermophilus also encodes an uncharacterized CARF domain-containing protein, TTHB144, which was reported to be Csm6-like [17]. Here we report that TTHB144 is also a potent CRISPR ancillary HEPN ribonuclease activated by $\mathrm{CA}_{4}$. Furthermore, 
the enzyme degrades $\mathrm{CA}_{4}$ using its CARF domain. This enzyme therefore represents the first known example of a cOA dependent enzyme that degrades its own activator.

\section{Results and Discussion}

The T. thermophilus HB8 type III CRISPR locus encodes three CARF domain containing proteins, TTHB144, TTHB152 and TTHB155 (Fig. 1a). A x-ray crystal structure is available for TTHB152 (PDB: $5 \mathrm{FSH}$ ) revealing a dimeric protein consisting of
$\mathrm{N}$-terminal CARF and C-terminal HEPN domains [10]. We modeled the structure of TTHB144 using the Phyre ${ }^{2}$ server [18], using TTHB152 as a template, and modeled $\mathrm{CA}_{4}$ into the electropositive pocket within the dimeric CARF domain (Fig. 1). Multiple sequence alignment identified highly conserved arginine and histidine residues within the HEPN domain characteristic of the Rx4-6H motif of HEPN nucleases [19]. Furthermore, we observed conserved lysine (K94) and threonine (T10/T11) residues within the ligand binding pocket of the CARF domain. By analogy with the ring nuclease Sso2081 [13], residues K94 and $\mathrm{T} 10 / \mathrm{T} 11$ are suitably positioned to interact with

(a)

Type III CRISPR locus of Thermus thermophilus HB8

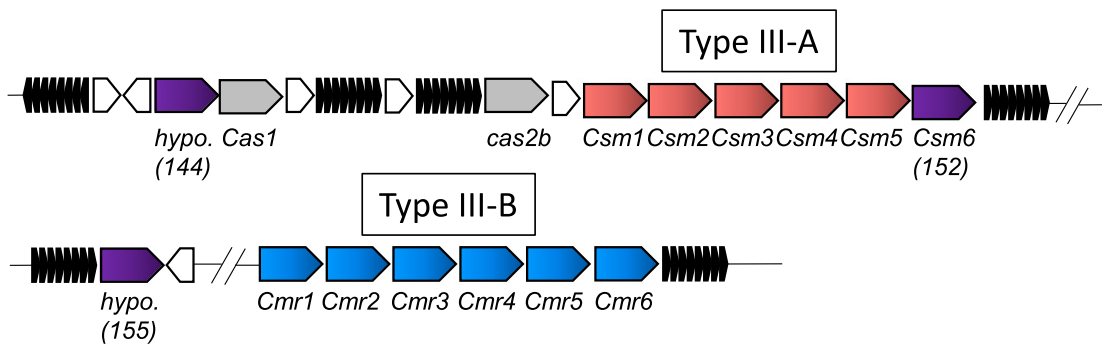

(b)

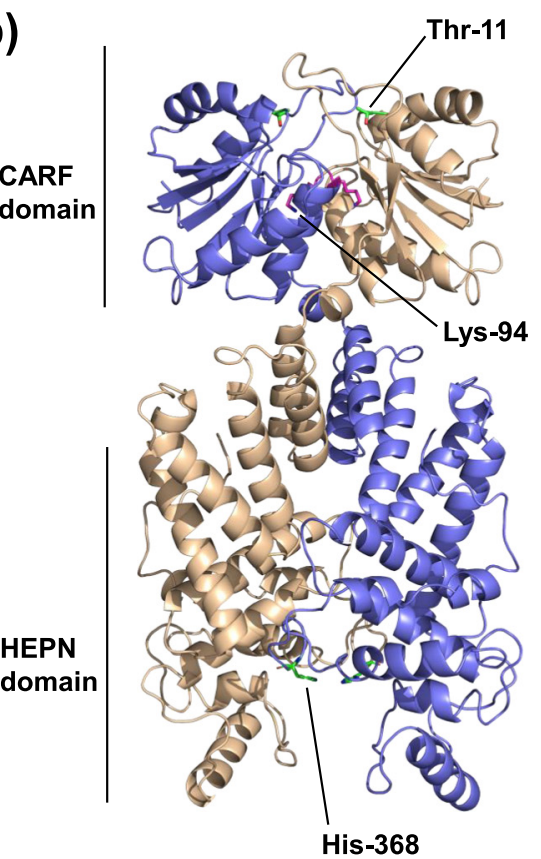

(c)

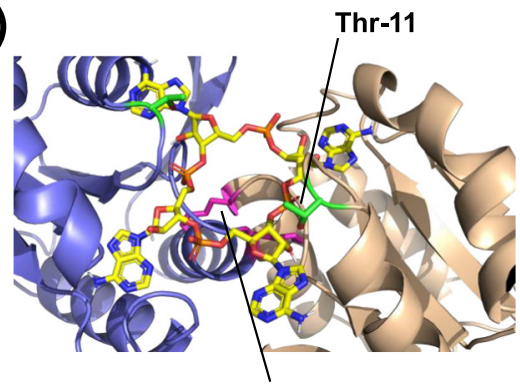

Lys-94

Fig. 1. Type III CRISPR locus of $T$. thermophilus HB8 (TTHB) and model structure of TTHB144 with $\mathrm{cA}_{4}$ bound. (a) Gene neighborhood of TTHB144 encoded on plasmid pTT27. Three genes encoding CARF domain-containing proteins (shown in purple) are present in the type III CRISPR locus of TTHB. TTHB152 is a Csm6 family protein, while TTHB144 and TTHB155 are hypothetical proteins of unknown function. (b) TTHB144 structure modeled using Phyre ${ }^{2}$. Each subunit of the predicted homodimer is shown by a different color (blue or cream). The highly conserved residues Thr-11, Lys-94 and His-368 are shown. (c) cA $_{4}$ modeled into the CARF domain of TTHB144. Lys-94 is situated centrally beneath the $\mathrm{CA}_{4}$ molecule, and the side-chain of Thr-11 is suitably positioned to interact with $\mathrm{CA}_{4}$. 
the $\mathrm{CA}_{4}$ ligand. Consequently, we constructed a synthetic gene encoding TTHB144, expressed the protein in Escherichia coli using the plasmid pEV5hisTEV [20] and purified the recombinant protein using immobilised metal affinity and size exclusion chromatography, using methods described previously [21]. Site-directed protein variants were constructed and purified as for the wild-type enzyme.

TTHB144 exhibited potent ribonuclease activity in the presence of $\mathrm{CA}_{4}$ and degraded RNA nonspecifically (Fig. 2a). The H368A variant, targeting the HEPN active site, had no RNase activity, confirming that TTHB144 is a canonical HEPN ribonuclease. The $\mathrm{T} 10 \mathrm{~A} / \mathrm{T} 11 \mathrm{~A}$ variant was still an active $\mathrm{CA}_{4}$-dependent ribonuclease, but the K94A variant was inactive, suggesting that $\mathrm{CA}_{4}$ no longer binds to activate the ribonuclease.

Subsequently, we assayed the rate of RNA degradation by TTHB144 under single-turnover conditions. TTHB144 fully degraded the RNA within $15 \mathrm{~s}$ (Fig. 2b), suggesting a lower limit of 5-10 $\mathrm{min}^{-1}$ for the catalytic rate constant. In addition, using the RNaseAlert ${ }^{\mathrm{TM}}$ fluorimetric assay system (Integrated DNA Technologies, USA) [6], we followed $\mathrm{CA}_{4}$ activated RNA cleavage by TTHB144 in a continuous assay (Fig. 2c). Consistent with observations made for other CRISPR ancillary ribonucleases such as Enterococcus italicus Csm6, Streptococcus thermophilus Csm6 and TTHB152 [10], this assay revealed weak TTHB144 ribonuclease activity, which was greatly enhanced by the addition of $\mathrm{CA}_{4}$.

To investigate whether TTHB144 degraded $\mathrm{CA}_{4}$, we incubated the wild-type protein with radiolabeled $\mathrm{CA}_{4}$ generated using the $S$. solfataricus type III-D Csm complex [21]. TTHB144 degraded $\mathrm{CA}_{4}$ to generate a slower migrating product on denaturing polyacrylamide gel electrophoresis (PAGE) (Fig. 2d), which we have previously identified as diadenylate containing a $5^{\prime}$ hydroxyl moiety and a $2^{\prime}, 3^{\prime}$-cyclic phosphate $\left(A_{2}>P\right)$ [13]. We verified this observation by high-resolution liquid chromatography-mass spectrometry, by comparison of $\mathrm{cA}_{4}$ degradation products with oligoadenylate standards generated using the E. coli MazF toxin, as described previously [21]. Similar to the $S$. solfataricus ring nucleases, TTHB144 degraded $\mathrm{CA}_{4}$ to yield an $\mathrm{A}_{4}>$ $P$ intermediate and $A_{2}>P$ product (Fig. 2e).

Subsequently, we evaluated $\mathrm{CA}_{4}$ degradation by TTHB144 CARF and HEPN domain variants. TTHB144 H368A, which has no ribonuclease activity, degraded $\mathrm{CA}_{4}$ similarly to wild-type protein, ruling out a role for the HEPN domain in $\mathrm{CA}_{4}$ degradation. However, $\mathrm{CA}_{4}$ degradation was abolished in the $\mathrm{K} 94 \mathrm{~A}$ variant and impaired in the T10A/T11A variant (Fig. 2d), suggesting a role for the CARF domain in this reaction. To confirm this hypothesis, we quantified the single-turnover rates of $\mathrm{CA}_{4}$ degradation by TTHB144 and its active site variants. The wild-type and $\mathrm{H} 368 \mathrm{~A}$ variant degraded $\mathrm{CA}_{4}$ at rates of $0.011 \pm 0.004$ and
$0.013 \pm 0.002 \mathrm{~min}^{-1}$, respectively (Fig. 3) allowing us to definitively rule out the HEPN domain as the site of $\mathrm{cA}_{4}$ degradation. The $\mathrm{K} 94 \mathrm{~A}$ variant was inactive, with no $\mathrm{CA}_{4}$ cleavage detectable over $2 \mathrm{~h}$, while the T10A/T11A variant, which remains a $\mathrm{CA}_{4}$-activated HEPN ribonuclease (Fig. 2a), exhibited a $\sim 12$-fold decrease $\left(k=0.001 \pm 0.002 \mathrm{~min}^{-1}\right)$ in $\mathrm{cA}_{4}$ cleavage rate compared to the wild-type protein. The rate of RNA degradation $\left(\sim 5-10 \mathrm{~min}^{-1}\right)$ thus appeared to exceed the rate of $\mathrm{CA}_{4}$ cleavage by approximately 3 orders of magnitude. Consequently, we investigated whether RNA binding at the HEPN domain stimulated $\mathrm{CA}_{4}$ degradation by the CARF domain by including unlabeled $\mathrm{RNA}$ in a $\mathrm{CA}_{4}$ degradation assay. TTHB144 degraded $\mathrm{CA}_{4}$ at a rate $(0.010 \pm$ $0.042 \mathrm{~min}^{-1}$ ) similar to $\mathrm{CA}_{4}$ degradation in the absence of RNA, suggesting that RNA binding at the HEPN domain does not affect $\mathrm{CA}_{4}$ degradation at the CARF domain.

To examine $\mathrm{CA}_{4}$ binding by the wild-type and variant enzymes, we carried out gel electrophoretic mobility shift assays with ${ }^{32} \mathrm{P}$-labeled $\mathrm{CA}_{4}$ (Fig. $3 \mathrm{c}$ ). The wildtype protein bound the $\mathrm{CA}_{4}$ ligand at protein dimer concentrations as low as $100 \mathrm{nM}$, with $100 \%$ binding at $1 \mu \mathrm{M}$ protein. In contrast, neither the T10A/T11A nor the $\mathrm{K} 94 \mathrm{~A}$ variants yielded detectable $\mathrm{CA}_{4}$ binding at protein dimer concentrations up to $20 \mu \mathrm{M}$. The highly conserved lysine residue $\mathrm{K} 94$ is clearly crucial for $\mathrm{CA}_{4}$ binding, and may also play a catalytic role during $\mathrm{CA}_{4}$ degradation. The T10 and T11 residues, which sit at the rim of the $\mathrm{CA}_{4}$ binding site, are also clearly important for $\mathrm{CA}_{4}$ binding, although the $\mathrm{T} 10 \mathrm{~A} / \mathrm{T} 11 \mathrm{~A}$ variant does retain the ability to degrade (and therefore bind) $\mathrm{CA}_{4}$ at a reduced level. Hence, the TTHB144 $\mathrm{CA}_{4}$ binding and cleavage mechanism may be similar to that of the crenarchaeal ring nuclease Sso2081, where the equivalent residues, S11 and $\mathrm{K} 106$, have been shown to be important for $\mathrm{CA}_{4}$ binding and/or cleavage [13].

\section{Conclusions}

TTHB144 is the first CARF family protein identified to harbor both $\mathrm{CA}_{4}$ degradation activity and ribonuclease activity. The single-turnover rate of $\mathrm{CA}_{4}$ degradation by TTHB144 at $70^{\circ} \mathrm{C}$ is slow: comparable to that of the less active $S$. solfataricus dedicated ring nuclease, Sso1393 [13]. This slow rate of $\mathrm{CA}_{4}$ degradation may function as a built-in control mechanism to limit the extent of ribonuclease activity. Faster rates of $\mathrm{CA}_{4}$ degradation could disable this arm of type III CRISPR-mediated immunity. Streptococcus epidermidis Csm6 activity during type III immunity has been shown to cause cell growth arrest [12], and self-limiting enzymes may be crucial for cell recovery following clearance of invading genetic entities in bacteria that do not have dedicated ring nucleases. 
(a)

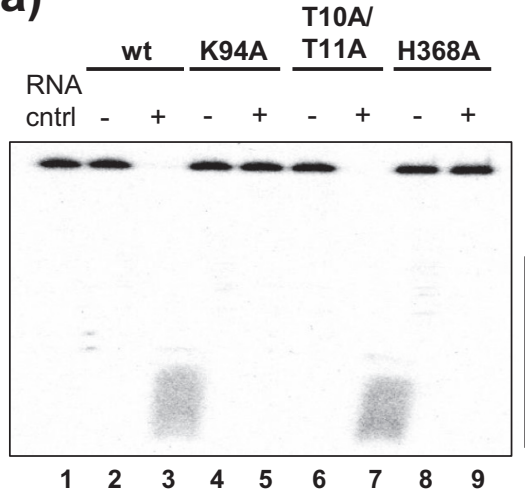

(c)

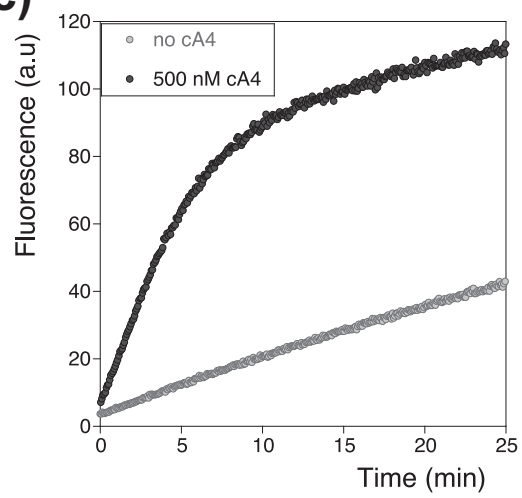

(b)

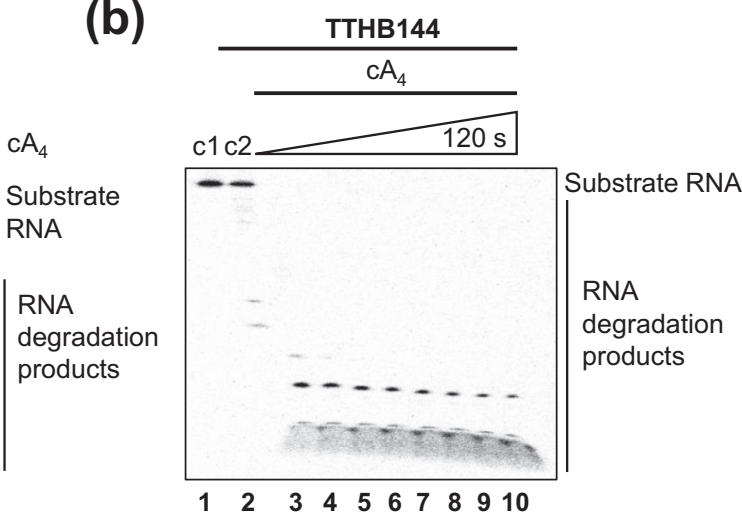

(e)

(d)
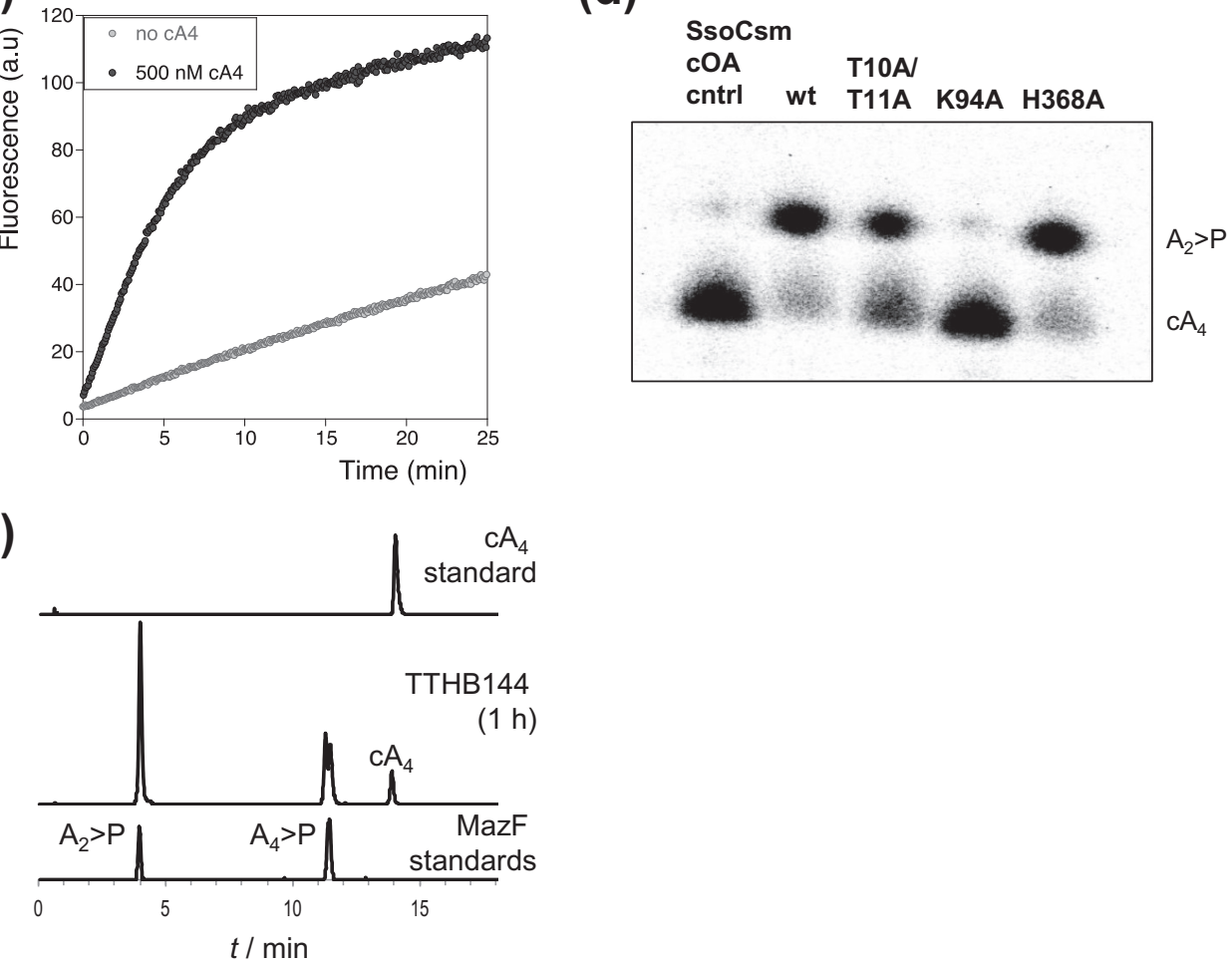

Fig. 2. RNA degradation and $\mathrm{cA}_{4}$ cleavage occur in separate domains of TTHB144. (a) Phosphorimage of denaturing PAGE visualizing the degradation of $50 \mathrm{nM}$ radiolabeled A1 RNA, as previously described [21], by TTHB144 (0.5 $\mu \mathrm{M}$ dimer), its CARF domain variants $\mathrm{K} 94 \mathrm{~A}$ and T10A/T11A and the HEPN domain variant H368A. The reaction was incubated at $70{ }^{\circ} \mathrm{C}$ for $60 \mathrm{~min}$ in $\mathrm{pH} 8.0$ buffer containing $20 \mathrm{mM}$ Tris- $\mathrm{HCl}, 150 \mathrm{mM} \mathrm{NaCl}, 1 \mathrm{mM}$ EDTA and 3 units SUPERase $/ \mathrm{n}^{\mathrm{TM}}$ inhibitor, before quenching by phenol-chloroform extraction. RNA was cleaved by wild-type (wt) protein and the T10A/T11A variant in the presence of $1 \mu \mathrm{M} \mathrm{cA}_{4}$, but not by the K94A or H368A variants. (b) Phosphorimage of denaturing PAGE visualizing degradation of $50 \mathrm{nM}$ radiolabeled RNA by TTHB144 (1 $\mu \mathrm{M}$ dimer) when incubated with

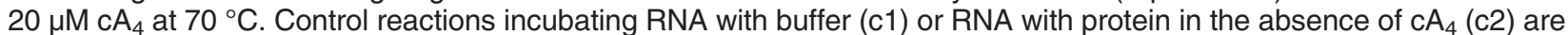
shown. All of the substrate RNA was degraded within $15 \mathrm{~s}$ (lane 3). (c) Plot of fluorescence emitted when RNaseAlert ${ }^{\mathrm{TM}}$ substrate $(1.5 \mu \mathrm{M}$; Integrated DNA Technologies) was degraded by $125 \mathrm{nM}$ dimer TTHB144 in the absence or presence of $500 \mathrm{nM} \mathrm{CA}_{4}$ at $50{ }^{\circ} \mathrm{C}$. Fluorimetry was carried out in a Cary Eclipse Fluorescence Spectrophotometer (Agilent Technologies) with excitation and emission wavelengths set to 490 and $520 \mathrm{~nm}$, respectively. (d) Phosphorimage of denaturing PAGE visualizing degradation of $400 \mathrm{nM}$ radiolabeled $\mathrm{cA}_{4}$ generated using SsoCsm complex, as previously described [21], by TTHB144 (4 $\mu \mathrm{M}$ dimer) and variants at $70{ }^{\circ} \mathrm{C}$ for $120 \mathrm{~min} . \mathrm{CA}_{4}$ was degraded to a slower migrating product. (e) High-resolution liquid chromatography mass spectrometry of $\mathrm{cA}_{4}$ produced using the SsoCsm complex and cleavage products generated on incubation with TTHB144 $(40 \mu \mathrm{M}$ dimer $)$ at $70^{\circ} \mathrm{C} . \mathrm{cA}_{4}(\sim 16 \mu \mathrm{M}$; top panel) was degraded to intermediate and product species (middle panel) with identical retention times to $A_{4}>P$ and $A_{2}>P$, respectively (bottom panel). $A_{4}>P$ and $A_{2}>P$ standards were generated using the $E$. coli MazF toxin as previously described [8]. 
(a)

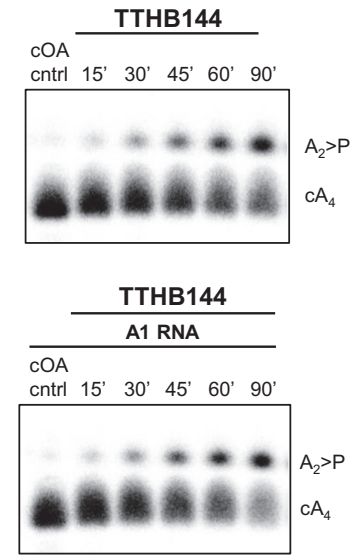

H368A

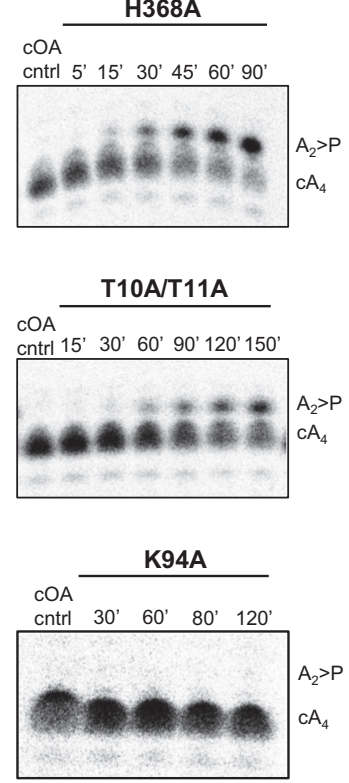

(b)

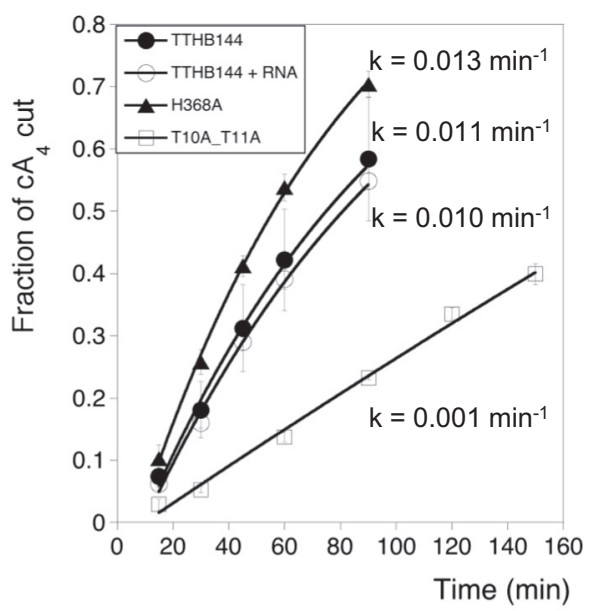

(c)

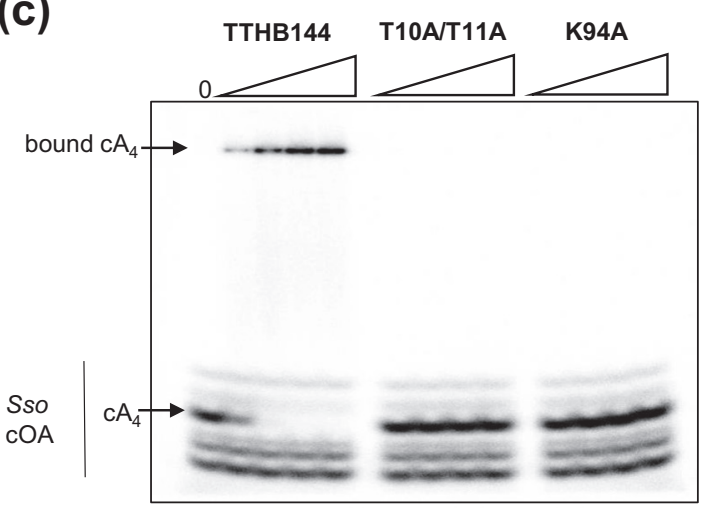

Fig. 3. $\mathrm{CA}_{4}$ binding and cleavage by wild-type and variant TTHB144 enzymes. (a) Panels are phosphorimages of denaturing PAGE visualizing degradation of $200 \mathrm{nM}$ radiolabeled $\mathrm{CA}_{4}$ by TTHB144 and variants $\left(8 \mu \mathrm{M}\right.$ dimer) at $70^{\circ} \mathrm{C}$. $\mathrm{CA}_{4}$ is degraded to $A_{2}>P$. Time in minutes is indicated. Protein and radiolabeled $\mathrm{cA}_{4}$ were incubated in $\mathrm{pH} 8.0$ buffer containing 20 $\mathrm{mM}$ Tris- $\mathrm{HCl}, 150 \mathrm{mM} \mathrm{NaCl}, 1 \mathrm{mM}$ EDTA and 3 units SUPERase $\bullet / \mathrm{n}^{\mathrm{TM}}$ inhibitor, and reactions were quenched at the indicated time-points by phenol-chloroform extraction. $\mathrm{A} \mathrm{CA}_{4}$ degradation assay was also carried out in the presence of $1 \mu \mathrm{M} A 1 \mathrm{RNA}$ in order to evaluate the effect of RNA binding and cleavage at the HEPN active site on $\mathrm{CA}_{4}$ degradation at the CARF domain. (b) Plot of the fraction of $\mathrm{CA}_{4}$ cut versus time, generated by quantifying the densiometric signals from the phosphorimages depicted in panel a. All data points are the average of at least three technical replicates and are fitted to an exponential rise equation to derive the rate of $\mathrm{CA}_{4}$ degradation, as described previously [21]. Data points for TTHB144 are the average of six replicates encompassing two biological replicates with three technical replicates for each. Error bars show the standard deviation of the mean. (c) Electrophoretic mobility shift assay of radioactively-labeled $\mathrm{cOA}$ generated by the $S$. solfataricus Csm complex. $\mathrm{CA}_{4}$ is indicated; minor bands correspond to linear and cyclic byproducts of the reaction. $\mathrm{CA}_{4}(20 \mathrm{nM})$ was incubated with TTHB144 or variants T10A/T11A or K94A $(0.1,1,10$ or $20 \mu \mathrm{M}$ protein dimer) in buffer containing $20 \mathrm{mM}$ Tris- $\mathrm{HCl}(\mathrm{pH} 7.5), 150 \mathrm{mM} \mathrm{NaCl}$ and $2 \mathrm{mM} \mathrm{MgCl}_{2}$ supplemented with $2 \mu \mathrm{M}$ Ultrapure Bovine Serum Albumin (Invitrogen) for 10 min at $25{ }^{\circ} \mathrm{C}$. A reaction volume equivalent of $20 \%(\mathrm{v} / \mathrm{v})$ glycerol was then added prior to loading the samples on a $15 \%$ polyacrylamide, $1 \times$ TBE gel. Electrophoresis was carried out at $25^{\circ} \mathrm{C}$ and $200 \mathrm{~V}$.

Therefore, the amalgamation of a HEPN ribonuclease and a ring nuclease into a single self-limiting enzyme may help decrease the toxicity associated with non-specific RNA cleavage in type III CRISPR systems.

\section{Acknowldgments}

This work was funded by a grant from the Biotechnology and Biological Sciences Research Council (Grant REF BB/S000313/1 to M.F.W.). 
Author Contribution Statement: J.S.A. carried out the investigation and analysis and wrote the original draft of the paper; S.Grü. and S.Gra. contributed to the investigation and analysis; M.F. W. conceptualized and supervised the work. All authors contributed to the review and editing.

Received 14 March 2019;

Received in revised form 22 April 2019; Available online 6 May 2019

\section{Keywords: \\ CRISPR; \\ anti-viral signaling; \\ cyclic oligoadenylate;}

ring nuclease, Thermus thermophilus

Present address: C. Rouillon, Max Planck Unit for the Science of Pathogens, Charitéplatz 1, 10117 Berlin,

Germany.

Abbreviations used:

CARF, CRISPR-associated Rossman fold; HEPN, Higher Eukaryotes and Prokaryotes Nucleotide binding; $\mathrm{COA}$, cyclic oligoadenylate; $\mathrm{CA}_{4}$, cyclic tetra-adenylate; TTHB,

Thermus thermophilus HB8.

\section{References}

[1] R. Barrangou, L.A. Marraffini, CRISPR-cas systems: prokaryotes upgrade to adaptive immunity, Mol. Cell. 54 (2014) 234-244.

[2] E.V. Koonin, K.S. Makarova, Mobile genetic elements and evolution of CRISPR-Cas systems: all the way there and back, Genome Biol. Evol. 9 (2017) 2812-2825.

[3] F. Hille, H. Richter, S.P. Wong, M. Bratovič, R. Sarah, E. Charpentier, The biology of CRISPR-Cas: backward and forward, Cell. 172 (2018) 1239-1259.

[4] G. Tamulaitis, Č. Venclovas, V. Siksnys, Type III CRISPRCas immunity: major differences brushed aside, Trends Microbiol. 25 (2017) 49-61.

[5] N.C. Pyenson, L.A. Marraffini, Type III CRISPR-Cas systems: when DNA cleavage just isn't enough, Curr. Opin. Microbiol. 37 (2017) 150-154.

[6] O. Niewoehner, C. Garcia-Doval, J.T. Rostøl, C. Berk, F. Schwede, L. Bigler, J. Hall, L.A. Marraffini, M. Jinek, Type III CRISPR-Cas systems produce cyclic oligoadenylate second messengers, Nature. 548 (2017) 543-548.

[7] M. Kazlauskiene, G. Kostiuk, Č. Venclovas, G. Tamulaitis, V. Siksnys, A cyclic oligonucleotide signaling pathway in type III CRISPR-Cas systems, Science. 357 (2017) 605-609.
[8] C. Rouillon, J.S. Athukoralage, S. Graham, S. Grüschow, M. F. White, Control of cyclic oligoadenylate synthesis in a type III CRISPR system, Elife. 7 (2018) 1-25.

[9] Y. Zhang, G. Montoya, S. Stella, K. Sulek, T. Guo, L. PengLundgren, Q. She, W. Han, A. Type, III-B Cmr effector complex catalyzes the synthesis of cyclic oligoadenylate second messengers by cooperative substrate binding, Nucleic Acids Res. 46 (2018) 10319-10330.

[10] O. Niewoehner, M. Jinek, Structural basis for the endoribonuclease activity of the type III-A CRISPR-associated protein Csm6, RNA. 22 (2016) 318-329.

[11] N.F. Sheppard, C.V.C. Glover, R.M. Terns, M.P. Terns, The CRISPR-associated Csx1 protein of Pyrococcus furiosus is an adenosine-specific endoribonuclease, RNA. 22 (2016) 216-224.

[12] J.T. RostøI, L.A. Marraffini, Non-specific degradation of transcripts promotes plasmid clearance during type III-A CRISPR-Cas immunity, Nat. Microbiol. 4 (2019) 656-662.

[13] J.S. Athukoralage, C. Rouillon, S. Graham, S. Grüschow, M.F. White, Ring nucleases deactivate type III CRISPR ribonucleases by degrading cyclic oligoadenylate, Nature. 562 (2018) 277-280.

[14] C.Y. Mo, L.A. Marraffini, If you'd like to stop a type III CRISPR ribonuclease, then you should put a ring (nuclease) on it, Mol. Cell. 72 (2018) 608-609.

[15] R.H.J. Staals, Y. Zhu, D.W. Taylor, J.E. Kornfeld, K. Sharma, A. Barendregt, J.J. Koehorst, M. Vlot, N. Neupane, K. Varossieau, K. Sakamoto, T. Suzuki, N. Dohmae, S. Yokoyama, P.J. Schaap, H. Urlaub, A.J.R. Heck, E. Nogales, J.A. Doudna, A. Shinkai, J. van der Oost, RNA targeting by the type III-A CRISPR-Cas Csm complex of Thermus thermophilus, Mol. Cell. 56 (2014) 518-530.

[16] T.Y. Liu, A.T. lavarone, J.A. Doudna, RNA and DNA targeting by a reconstituted Thermus thermophilus Type III-A CRISPR-Cas system, PLoS One. 12 (2017), e0170552.

[17] S.A. Shah, O.S. Alkhnbashi, J. Behler, W. Han, Q. She, W.R. Hess, R.A. Garrett, R. Backofen, Comprehensive search for accessory proteins encoded with archaeal and bacterial type III CRISPR-cas gene cassettes reveals 39 new cas gene families, RNA Biol. (2018) 1-13.

[18] L.A. Kelley, S. Mezulis, C.M. Yates, M.N. Wass, M.J.E. Sternberg, The Phyre2 web portal for protein modeling, prediction and analysis, Nat. Protoc. 10 (2015) 845-858.

[19] V. Anantharaman, K.S. Makarova, A.M. Burroughs, E.V. Koonin, L. Aravind, Comprehensive analysis of the HEPN superfamily: Identification of novel roles in intra-genomic conflicts, defense, pathogenesis and RNA processing, Biol. Direct. 8 (2013).

[20] H. Liu, J.H. Naismith, A simple and efficient expression and purification system using two newly constructed vectors, Protein Expr. Purif. 63 (2009) 102-111.

[21] C. Rouillon, J.S. Athukoralage, S. Graham, S. Grüschow, M.F. White, Investigation of the cyclic oligoadenylate signaling pathway of type III CRISPR systems, Methods Enzymol. 616 (2019) 191-218. 